\title{
Lack of association between provocative test-based intraocular pressure parameters and functional loss in treated glaucoma patients
}

\section{Falta de associação entre parâmetros de pressão intraocular obtidos pelo teste de sobrecarga hídrica e dano funcional em pacientes com glaucoma}

\author{
Ana Luiza Bassoli Scoralick1,2,3, Carolina Pelegrini Barbosa Gracitelli1, Diego Torres Dias ${ }^{1,2}$, Izabela Almeida',2, \\ Michele Ushida², Syril Dorairaj ${ }^{4}$, Fábio Nishimura Kanadani ${ }^{3,4}$, Augusto Paranhos Jr.', Tiago Santos Prata $1,2,4$ \\ 1. Glaucoma Service, Department of Ophthalmology, Universidade Federal de São Paulo, São Paulo, SP, Brazil. \\ 2. Glaucoma Unit, Hospital Medicina dos Olhos, Osasco, SP, Brazil. \\ 3. Department of Ophthalmology, Instituto de Olhos Ciências Médicas, Belo Horizonte, MG, Brazil. \\ 4. Department of Ophthalmology, Mayo Clinic, Jacksonville, FL, USA
}

\begin{abstract}
Purpose: To correlate provocative test-based intraocular pressure (IOP) variation parameters (fluctuation and peak) with functional status, and to compare these IOP parameters between treated eyes with asymmetric primary open-angle glaucoma (POAG). Methods: A prospective observational study including consecutively treated patients with primary open-angle glaucoma was performed. Subjects with ocular diseases other than glaucoma or previous incisional glaucoma surgery were excluded. The primary inclusion criteria were $\geq 3$ visual field tests and $\geq 2$ years of follow-up, without any changes on current medical regimen. Long-term intraocular pressure parameters were acquired via isolated intraocular pressure measurements from the patients' last 5 office visits. To evaluate provocative test-based intraocular pressure parameters, all patients were submitted to a water drinking test. Initially, the partial correlation coefficients between each intraocular pressure variation parameter and visual field mean deviation were calculated, adjusting for the baseline intraocular pressure and number of antiglaucoma medications. In addition, each intraocular pressure parameter was compared between eyes with better visual field mean deviation and fellow eyes with worse visual field mean deviation in patients with asymmetric visual field loss (defined as an inter-eye visual field mean deviation difference of at least $3 \mathrm{~dB}$ ). Results: A total of 87 eyes (87 patients; mean age, $61.9 \pm 12.5$ years; $59.8 \%$ women)
\end{abstract}

Submitted for publication: February 26, 2018

Accepted for publication: September 15, 2018

Correspondence author: Tiago Prata

Rua Dr. José Rodrigues Alves Sobrinho, 125 - São Paulo, SP - 05466-040 - Brazil E-mail: tiagoprata@ig.com.br

Funding: No specific financial support was available for this study.

Disclosure of potential conflicts of interest: None of the authors have any potential conflicts of interest to disclose.

Approved by the following research ethics committee: Universidade Federal de São Paulo - EPM/UNIFESP (CAAE: 61424616.0.0000.5505). with primary open-angle glaucoma were included. The patients underwent a median of 5 visual field tests, with a mean follow-up of $4.3 \pm 1.4$ years. Neither long-term nor water-drinking test intraocular pressure variation parameters were significantly associated with visual field mean deviation values $(p \geq 0.117)$. In the subgroup with asymmetric visual field loss (64 eyes of 32 patients; mean age, $65.0 \pm 11.4$ years), neither long-term water-drinking test intraocular pressure variation parameters differed significantly between eyes with better and worse visual field mean deviation $(\mathrm{p} \geq 0.400)$. Conclusion: Our results indicate that neither long-term intraocular pressure variation parameters nor stress test-derived intraocular pressure metrics, as assessed by the water-drinking test, appear to correlate with the visual field status or differ significantly between eyes with asymmetric visual field damage, suggesting that other factors may explain such functional asymmetry, and that the water-drinking test does not add significant information to these cases.

Keywords: Glaucoma, open-angle/physiopathology; Intraocular pressure/physiology; Diagnostic techniques, ophthalmological; Drinking; Water; Circadian rhythm

RESUMO | Objetivo: Correlacionar os parâmetros de variação da pressão intraocular (flutuação e pico) com o dano funcional em pacientes tratados com glaucoma primário de ângulo aberto, e comparar esses parâmetros de pressão intraocular entre olhos com dano funcional assimétrico. Métodos: Estudo observacional prospectivo foi realizado incluindo consecutivamente pacientes tratados com glaucoma primário de ângulo aberto. Foram excluídos indivíduos com outras doenças oculares que não o glaucoma ou cirurgia prévia incisional de glaucoma. Os principais critérios de inclusão foram: $\geq 3$ testes de campo visual e $\geq 2$ anos de acompanhamento, sem quaisquer alterações no regime medicamentoso atual. Parâmetros de pressão intraocular de longo prazo foram obtidos através de medidas de pressão 
intraocular isoladas de cada consulta (as últimas 5 consultas de cada paciente foram consideradas para análise). Para avaliação dos parâmetros de pressão intraocular de curto prazo, todos os pacientes foram submetidos ao teste de sobrecarga hídrica. Inicialmente, calculamos os coeficientes de correlação parcial de cada parâmetro de variação da pressão intraocular com o nível de dano funcional, baseado no índice Mean Deviation (MD), ajustando para a pressão intraocular basal e o número de medicações antiglaucomatosas. Além disso, comparamos cada parâmetro de pressão intraocular entre os olhos com melhor e pior nível de dano funcional em pacientes com perda de campo visual assimétrica (definida como diferença no índice mean deviation entre os olhos de pelo menos $3 \mathrm{~dB}$ ). Resultados: Foram incluídos 87 olhos (87 pacientes) com glaucoma primário de ângulo aberto. A idade média foi de $61,9 \pm 12,5$ anos e $59,8 \%$ eram mulheres. Em geral, os pacientes foram submetidos a 5 testes (mediana) de campo visual, com um seguimento médio de 4,3 \pm 1,4 anos. Nem os parâmetros de variação da pressão intraocular de longo prazo nem aqueles obtidos pelo teste de sobrecarga hídrica se correlacionaram significativamente com o nível de dano no campo visual $(\mathrm{p} \geq 0,117)$. No subgrupo com perda de campo visual assimétrica (64 olhos de 32 pacientes; idade média, 65,0 \pm 11,4 anos), nem os parâmetros de variação da pressão intraocular de longo prazo nem os obtidos pelo teste de sobrecarga hídrica diferiram significativamente entre olhos com melhor e pior nível de dano funcional ( $p \geq 0,400$ ). Conclusão: Nossos resultados indicam que não apenas parâmetros de variação da pressão intraocular de longo prazo, mas também medidas de pressão intraocular derivadas do teste de sobrecarga hídrica, não parecem se correlacionar com o nível de dano do campo visual, nem diferem significativamente entre olhos com nível de dano funcional assimétrico. Esses achados sugerem que outros fatores poderiam explicar essa assimetria funcional e que o teste de sobrecarga hídrica não acrescenta informações significativas a esses casos.

Descritores: Glaucoma de ângulo aberto; Pressão intraocular/ fisiologia; Técnicas de diagnóstico oftalmológico; Ingestão de líquidos; Água; Ritmo circadiano

\section{INTRODUCTION}

Glaucoma is an optic neuropathy characterized by progressive structural and functional damage. Intraocular pressure (IOP) is the most important known risk factor for disease development and progression ${ }^{(1,2)}$. Hence, the primary goal of glaucoma treatment is the effective reduction of $\mathrm{IOP}^{(3)}$. Although IOP is a key parameter, it varies significantly due to factors associated with the measurement itself (type of tonometer, the examiner, fluorescein, circadian cycle) ${ }^{(4)}$, individual patient/ocular factors (central corneal thickness $^{(5)}$, corneal hysteresis ${ }^{(5)}$, dehydration ${ }^{(6)}$, glucose levels ${ }^{(7)}$, fasting) ${ }^{(6)}$, and other factors such as medical regimen, systemic/ocular comorbidities, and ocular disease characteristics ${ }^{(4-7)}$.
In this context, many studies have examined IOP variation patterns and their relationship with glaucoma management ${ }^{(8,9)}$. Typically, IOP variation parameters are classified into long- and short-term parameters. Long-term parameters are evaluated by longitudinal IOP measurements (based on different office visits), while short-term IOP parameters (daily IOP profile) are derived usually from tension curves ${ }^{(10)}$. In addition, patients' short-term IOP profiles may be estimated by provocative tests, such as the water drinking test (WDT) ${ }^{(11,12)}$.

Although it is a bilateral disease, many studies have reported on asymmetric primary open-angle glaucoma (POAG) $^{(13-17)}$. Although several factors possibly related to functional asymmetry between POAG eyes have been investigated ${ }^{(13-16)}$, such an asymmetry could be explained in part by differences in the IOP profile between eyes. Although similar treated IOP values are expected during office visits between both eyes of a patient with POAG, long-term IOP variation parameters (fluctuation and peak), and especially those derived from provocative tests, could differ between eyes and justify an asymmetry in functional status. The primary aim of this study was to correlate provocative test-based IOP variation parameters with functional status in POAG eyes. A secondary aim was to compare IOP parameters between treated eyes with asymmetric functional damage.

\section{METHODS}

This prospective observational study adhered to the principles of the Declaration of Helsinki and was approved by the Institutional Review Board of the Federal University of São Paulo. In addition, written informed consent was obtained from all study participants.

\section{Patients and data collection}

The present study enrolled consecutive patients with POAG undergoing a complete ophthalmological examination, including a review of medical history, best-corrected visual acuity, IOP measurement with Goldmann applanation tonometry, slit-lamp biomicroscopy, gonioscopy, refraction, and dilated fundus examination. Patients were classified as having (or not) asymmetric functional glaucomatous damage if they presented an inter-eye difference in visual field mean deviation (VFMD) index of at least $3 \mathrm{~dB}$.

The primary inclusion criteria were $\geq 3$ visual field (VF) tests and $\geq 2$ years of follow-up, without any changes on current medical regimen. The included patients had 
to have glaucomatous optic neuropathy associated with characteristic VF defects and open angle on gonioscopy. Glaucomatous optic neuropathy was defined as a vertical cup-to-disc ratio (VCDR) $\geq 0.6$, VCDR asymmetry $\geq 0.2$ between eyes, and localized or diffuse peripapillary retinal nerve fiber layer defects, and/or neuroretinal rim defects without any other abnormalities to explain such findings ${ }^{(18,19)}$. All VFs were measured using the 24-2 Swedish Interactive Threshold Algorithm (Humphrey Field Analyzer II, Carl Zeiss Meditec, Inc., Dublin, CA, USA). Patients were excluded if presenting $>33 \%$ fixation losses or false-negative errors or $>15 \%$ false-positive errors. VFs were reviewed and eliminated in the presence of artifacts, including lid or rim artifacts, fatigue effects, inattention, or inappropriate fixation in addition to abnormalities that could indicate diseases other than glaucoma.

\section{Assessment of long-term and provocative test-based IOP parameters}

Peak and fluctuation (as variability metrics) were investigated as long-term and provocative test-based IOP variation parameters. In addition, the mean IOP was calculated (as a central tendency metric). Long-term IOP parameters were acquired by isolated IOP measurements taken at each office visit. Each long-term parameter was assessed using a minimum of 5 IOP measurements. In order to acquire provocative test-based IOP parameters, all patients were submitted to a WDT, as proposed by Susanna et al., consisting of 1 baseline IOP measurement, followed by 3 other IOP measurements taken at 15-minute intervals after the patient ingests $800 \mathrm{~mL}$ of tap water in 5 minutes ${ }^{(11)}$. All participants were required to fast for $2 \mathrm{~h}$ before the test.

\section{Statistical analysis and sample size calculation}

Demographic and clinical data were presented using descriptive analysis. The D'Agostino-Pearson test was performed to determine whether the data were normally distributed. Descriptive statistics included the mean and standard deviation for normally distributed variables, and the median and quartiles for non-normally distributed variables. Initially, partial correlation coefficients between each IOP variation parameter and the VFMD index were calculated, adjusting for the baseline IOP (defined as the IOP measurement recorded on the patient's last visit) and number of antiglaucoma medications. VFMD sensitivity absolute values (rather than converting from decibels to linear units) were used as this type of approach is recommended typically for plots showing structure-function relationships. When both eyes were eligible, one was randomly selected for analysis. Next, each IOP parameter was compared between the group of eyes with better VFMD values and the group of fellow eyes with worse MD values in the subgroup of patients with asymmetric glaucoma. Normally distributed IOP parameters were compared using paired sample $t$-test, while the Wilcoxon test was used to compare the non-normally distributed parameters.

The correlation between the WDT IOP peak and the VFMD index was the parameter chosen to calculate the sample size. Considering an alpha error of 0.05 and a hypothesized/anticipated correlation coefficient of 0.3 , a minimum of 84 patients would be necessary to reach a power of $80 \%$. MedCalc statistical software (MedCalc Inc., Mariakerke, Belgium) was used to perform computer analysis. The alpha level (type l error) was set at 0.05 .

\section{RESULTS}

A total of 87 eyes (87 patients; mean age, $61.9 \pm$ 12.5 years; $59.8 \%$ women) with POAG was included. The patients underwent a median of 5 (interquartile interval, 4.0-6.0) VF tests, with a mean follow-up of $4.3 \pm$ 1.4 years. Overall, the mean baseline IOP was $13.4 \pm$ $2.9 \mathrm{mmHg}$, and the mean number of antiglaucoma medications was $1.7 \pm 0.9$. The demographic and ocular characteristics of study patients are detailed in table 1 .

Table 1. Demographic and ocular characteristics of study patients

\begin{tabular}{lc}
\hline Variables* & Group $(\mathbf{n = 8 7})$ \\
\hline Age (years) & $61.9 \pm 12.5$ \\
Sex (female/male) & $52(59.8 \%) / 35(40.2 \%)$ \\
Race (white/other) & $58(67.4 \%) / 28(32.6 \%)$ \\
Central corneal thickness $(\mu \mathrm{m})$ & $506.7 \pm 35.5$ \\
Follow-up (years) & $4.3 \pm 1.4$ \\
Baseline intraocular pressure (mmHg) & $13.4 \pm 2.9$ \\
Number of antiglaucoma medications & $5(4.0,6.0)$ \\
Number of visual field tests & $-2.6(-7.3,-1.0)$ \\
Visual field mean deviation index $(\mathrm{dB})$ & $96.0(84.0,99.0)$ \\
\hline Visual field index $(\%)$ & \pm standard deviation, and \\
\hline *Normally distributed variables are presented as mean & 1.9 \\
non-normally distributed variables are described as median and interquartile interval.
\end{tabular}


Neither long-term nor WDT IOP variation parameters were associated significantly with the VF status as assessed by VFMD values ( $\mathrm{p} \geq 0.117)$. Correlations between the long-term IOP fluctuation $(r=0.08, p=0.446)$ and peak $(\mathrm{r}=0.08, \mathrm{p}=0.475)$ with VFMD are shown in figures $1 \mathrm{~A}$ and $1 \mathrm{~B}$, respectively. Correlations between the WDT IOP fluctuation $(r=0.17, p=0.117)$ and peak $(r=0.15$, $p=0.160$ ) with VFMD are shown in figures $2 A$ and $2 B$, respectively. Our secondary analysis showed that neither long-term mean IOP $(r=0.06, p=0.598)$ nor WDT mean IOP $(r=0.15, p=0.155)$ were correlated significantly with VFMD values.

In total, 64 eyes (32 patients; mean age, $65.0 \pm 11.4$ years) comprised the subgroup with asymmetric glaucomatous VF loss. The patients underwent a median of 5.0 (interquartile interval, 4.0-6.0) VF tests, with a mean follow-up of $4.1 \pm 1.1$ years. The number of antiglaucoma medications and baseline IOP values did not differ significantly between eyes with better and worse VFMD values $(p=0.354)$, and neither long-term nor WDT IOP variation parameters differed significantly between eyes with better and worse VFMD ( $p \geq 0.400)$. Table 2 provides a more comprehensive comparison of each IOP parameter.

\section{DISCUSSION}

As discussed previously, some patients may present with asymmetric POAG ${ }^{(13-17)}$. This prospective study investigated whether the IOP variation profile could be related to patients' current functional status. In evaluating almost 90 consecutively treated patients with POAG with various disease stages (VF index range, 11-100\%), we found that neither long-term nor WDT IOP variation parameters correlated significantly with patients' VF status or differed between eyes with better and worse VFMD values.
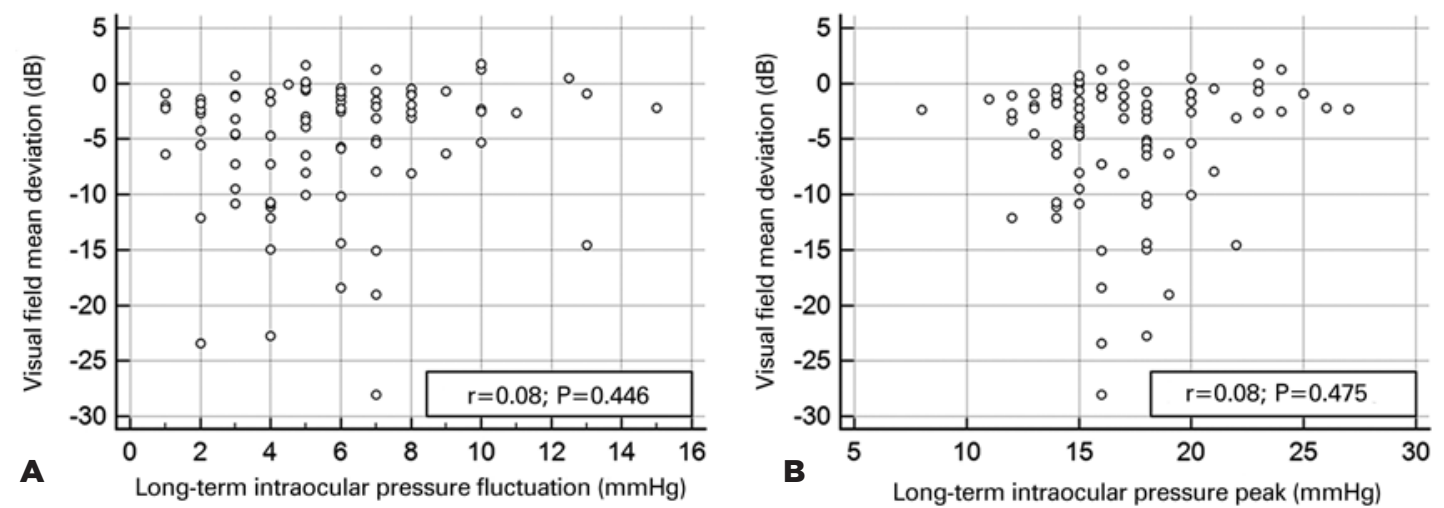

Figure 1. Scatterplot depicting the correlation between the long-term IOP fluctuation and VFMD (A); scatterplot depicting the correlation between the long-term IOP peak and VFMD (B). Partial correlation coefficients and p-values are also provided (adjusted for the baseline IOP and number of antiglaucoma medications).
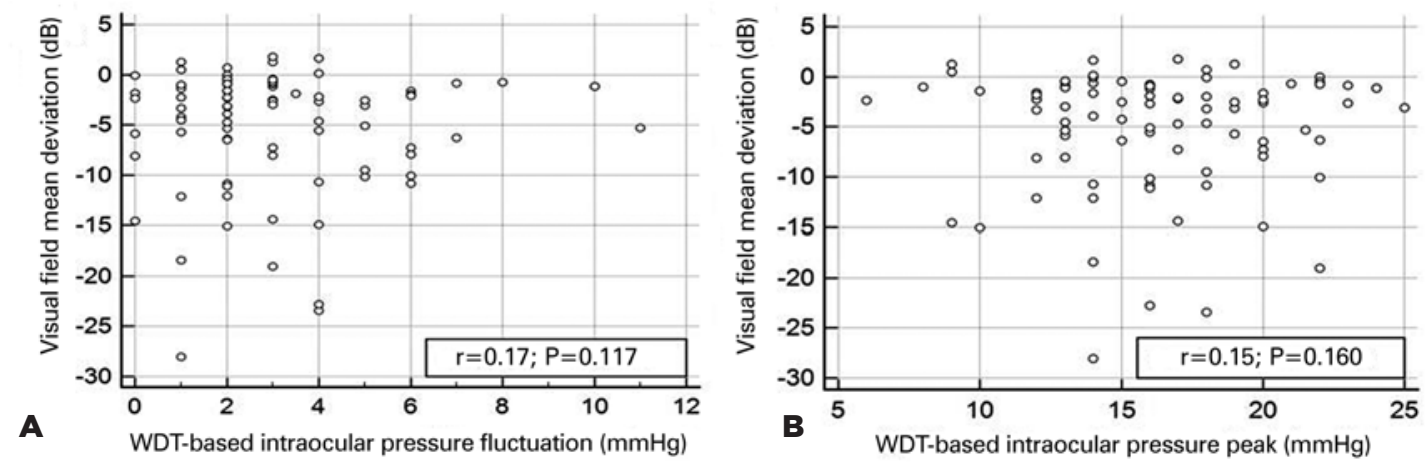

Figure 2. Scatterplot depicting the correlation between the WDT IOP fluctuation and VFMD (A); scatterplot depicting the correlation between the WDT IOP peak and VFMD (B). Partial correlation coefficients and p-values are also provided (adjusted for the baseline IOP and number of antiglaucoma medications). 
Table 2. Characteristics of eyes with better and worse visual field mean deviation values

\begin{tabular}{lccc}
\hline Variables & Eyes with better VFMDs & Eyes with worse VFMDs & P-value \\
\hline CCT $(\mu \mathrm{m})$ & $509.3 \pm 31.3$ & $511.5 \pm 30.9$ & 0.212 \\
VFMD $(\mathrm{dB})$ & $-2.6(-4.8,-0.7)$ & $-9.8(-12.1,-6.2)$ & $<0.001$ \\
VFI (\%) & $95.5(86.5,99.0)$ & $78.5(69.0,88.0)$ & $<0.001$ \\
Number of antiglaucoma medications & $1.7 \pm 0.8$ & $1.8 \pm 0.9$ & 0.354 \\
Baseline IOP $(\mathrm{mmHg})$ & $13.5 \pm 2.6$ & $13.4 \pm 2.5$ & 0.670 \\
LT IOP mean $(\mathrm{mmHg})$ & $13.8 \pm 2.1$ & $14.0 \pm 1.8$ & 0.452 \\
LT IOP peak (mmHg) & $16.2 \pm 2.8$ & $16.6 \pm 2.6$ & 0.400 \\
LT IOP fluctuation $(\mathrm{mmHg})$ & $5.0(2.5,7.0)$ & $5.0(4.0,6.0)$ & 0.829 \\
WDT IOP mean $(\mathrm{mmHg})$ & $14.7 \pm 3.0$ & $14.8 \pm 2.9$ & 0.851 \\
WDT IOP peak (mmHg) & $15.8 \pm 3.4$ & $16.0 \pm 3.5$ & 0.748 \\
WDT IOP fluctuation $(\mathrm{mmHg})$ & $2.8 \pm 1.7$ & $2.9 \pm 1.7$ \\
\hline
\end{tabular}

$\mathrm{CCT}=$ central corneal thickness; $\mathrm{VFMD}=$ visual field mean deviation index; $\mathrm{VFI}=$ visual field index; $\mathrm{LT}=$ long-term; $\mathrm{IOP}=\mathrm{intraocular}$ pressure; $\mathrm{WDT}=\mathrm{water}$ drinking test. *Normally distributed variables are presented as mean \pm standard deviation, and non-normally distributed variables are described as median and interquartile interval.

Many previously published prospective and robust studies have investigated the association between IOP parameters (derived primarily from assessing long-term variations in IOP) and disease development or progres$\operatorname{sion}^{(3,20-25)}$. In general, their findings are conflicting, and there is still no consensus on which is the most adequate IOP parameter for glaucoma management ${ }^{(23,24,26)}$. Conversely, data on the relationship between IOP variation parameters and asymmetric glaucoma are scant. Cartwright et al. performed a retrospective analysis of 14 glaucomatous eyes with asymmetric IOP (1-6 mmHg interocular difference in IOP) ${ }^{(16)}$ and found that glaucomatous cupping and VF loss were greater in the eye with higher IOP values in $85 \%$ of the cases. It should be emphasized that, different from our study, Cartwright et al.'s study population comprised eyes with normal-tension glaucoma and asymmetric IOP. The authors also noted that other factors could account for the instances in which asymmetric damage did not reflect a difference in IOP.

Regarding provocative test-based IOP parameters, retrospective data suggested that an individual ocular response to the WDT could be related to the stage of glaucomatous damage ${ }^{(17)}$. In a retrospective study of 101 eyes with POAG and asymmetric VF loss, Susanna et al. ${ }^{(17)}$ reported that eyes with worse VFMDs had a greater IOP peak and fluctuation during the WDT. When comparing fellow eyes with significant differences in VFMD (mean MD in groups with better and worse VF damage was -4.6 and $-9.0 \mathrm{~dB}$, respectively), they found a mean IOP peak difference of $0.7 \mathrm{mmHg}$ and a mean difference in the IOP fluctuation of $0.8 \mathrm{mmHg}^{(17)}$. In their conclusions, the authors stated that their findings demonstrated that eyes with worse glaucomatous damage had a lower capacity to respond to the WDT stimulus, leading to transient IOP elevation ${ }^{(17)}$. Although such differences were statistically significant, their clinical significance appears to be questionable (mean differences $<1 \mathrm{mmHg}$ ). In the present study, we also detected small mean differences $(<0.3 \mathrm{mmHg})$ in both the IOP peak and fluctuation during the WDT between eyes with better and worse VF damage and no significant correlations between WDT-based IOP parameters and VFMD values. Therefore, we believe that our results are not conflicting, but rather corroborate the previously reported data ${ }^{(17)}$.

We believe it is important to discuss the main clinical implications of our findings. While treating patients with POAG with asymmetric damage and similar office IOP measurements, physicians could be inclined to investigate patients' IOP variation profiles, especially with provocative tests, and the results of such an investigation could even be used in managing these patients. The rationale is that an eye with more advanced disease would have a more impaired outflow system and thus a more pronounced pressure response (IOP fluctuation and peak) to the WDT. Our results suggest that the IOP response to the WDT does not differ significantly between fellow eyes with asymmetric glaucoma in unoperated patients with POAG within this age range, under a similar medical regimen, and within this range of asymmetric VF loss. In this context, the WDT would not add any significant information to these cases. Therefore, we can assume that other factors not investigated in the present study could be related to patients' VF status and would 
better explain the asymmetric VF loss between fellow eyes. Vascular mechanisms $s^{(14,15,27,28)}$, lateral decubitus ${ }^{(13)}$, and preferred sleeping side ${ }^{(29)}$ are among the factors investigated previously in eyes with asymmetric glaucoma. We can also deduce that factors, such as differences in the time of disease onset, untreated IOP values, and level of glaucomatous damage between eyes at the time of diagnosis, should be considered.

Some specific characteristics and limitations of the present study that should be stressed are that our findings are limited to this specific population and therefore should not be extrapolated to patients with distinct characteristics. In addition, due to its cross-sectional design, our study did not allow an investigation of cause-effect relationships, but rather associations. Moreover, we included treated patients, and patients' medical regimen may influence their response to the WDT. The fact that we did not find significant differences in the number of medications between fellow eyes and that we adjusted our analyses for antiglaucoma medications and baseline IOP values certainly mitigated this issue. Furthermore, our findings have no relationship with glaucoma prognosis. A longitudinal analysis or a case-control study is necessary to evaluate the relationship between these IOP variation parameters and glaucoma stability over time. Finally, the fact that the study included treated patients who adhered strictly to their current medical regimen may indicate good disease control in this group of patients, which may have influenced our findings.

In summary, our results indicate that neither long-term IOP variation parameters nor stress test-derived IOP metrics as assessed by the WDT appear to correlate with patients' VF status or differ significantly between eyes with asymmetric VF damage. These findings suggest that other factors may explain such functional asymmetry, and that the WDT does not add significant information to these cases.

\section{REFERENCES}

1. Weinreb RN, Khaw PT. Primary open-angle glaucoma. Lancet. 2004;363(9422):1711-20. Comment in: Lancet. 2004;364(9442): 1311-2.doi:10.1016/S0140-6736(04)16257-0.

2. Comparison of glaucomatous progression between untreated patients with normal-tension glaucoma and patients with therapeutically reduced intraocular pressures. Collaborative Normal-Tension Glaucoma Study Group. Am J Ophthalmol. 1998;126(4):487-97. Erratum in: Am J Ophthalmol. 1999;127(1):120.

3. Heijl A, Leske MC, Bengtsson B, Hyman L, Bengtsson B, Hussein M, Early Manifest Glaucoma Trial Group. Reduction of intraocular pressure and glaucoma progression: results from the Early Manifest Glaucoma Trial. Arch Ophthalmol. 2002;120(10):1268-79.
4. Sit AJ, Nau CB, McLaren JW, Johnson DH, Hodge D. Circadian variation of aqueous dynamics in young healthy adults. Invest Ophthalmol Vis Sci. 2008;49(4):1473-9.

5. Kotecha A1, Crabb DP, Spratt A, Garway-Heath DF. The relationship between diurnal variations in intraocular pressure measurements and central corneal thickness and corneal hysteresis. Invest Ophthalmol Vis Sci. 2009;50(9):4229-36.

6. Oltulu R, Satirtav G, Ersan I, Soylu E, Okka M, Zengin N. The effect of dehydration and fasting on corneal biomechanical properties and intraocular pressure. Eye Contact Lens. 2016;42(6):392-4.

7. Pimentel LG, Gracitelli CP, da Silva LS, Souza AK, Prata TS. Association between Glucose levels and intraocular pressure: pre-and postprandial analysis in diabetic and nondiabetic patients. J Ophthalmol. 2015;2015;832058.

8. Medeiros FA, Weinreb RN, Zangwill LM, Alencar LM, Sample PA, Vasile $\mathrm{C}$, et al. Long-term intraocular pressure fluctuations and risk of conversion from ocular hypertension to glaucoma. Ophthalmology. 2008;115(6):934-40.

9. Zeimer RC, Wilensky JT, Gieser DR, Viana MA. Association between intraocular pressure peaks and progression of visual field loss. Ophthalmology. 1991;98(1):64-9.

10. Cronemberger S, Silva AC, Calixto N. Importance of intraocular pressure measurement at 6:00 a.m. in bed and in darkness in suspected and glaucomatous patients. Arq Bras Oftalmol. 2010; 73(4):346-9.

11. Susanna R Jr, Clement C, Goldberg I, Hatanaka M. Applications of the water drinking test in glaucoma management. Clin Experiment Ophthalmol. 2017;45(6):625-31.

12. Kanadani FN, Moreira T, Campos LF, Vianello MP, Corradi J, Dorairaj SK, et al; A new provocative test for glaucoma. J Curr Glaucoma Pract. 2016;10(1):1-3.

13. Tang J, Li N, Deng YP, Qiu LM, Chen XM. Effect of body position on the pathogenesis of asymmetric primary open angle glaucoma. Int J Ophthalmol. 2018;11(1):94-100.

14. Kac MJ, Solari HP, Velarde GC, Brazuna R, Cardoso GP, Ventura MP. Ocular pulse amplitude in patients with asymmetric primary open-angle glaucoma. Curr Eye Res. 2011;36(8):727-32.

15. Costa VP, Sergott RC, Smith M, Spaeth GL, Wilson RP, Moster MR, et al. Color Doppler imaging in glaucoma patients with asymmetric optic cups. J Glaucoma. 1994;3 Suppl 1:S91.

16. Cartwright MJ, Anderson DR. Correlation of asymmetric damage with asymmetric intraocular pressure in normal-tension glaucoma (low-tension glaucoma). Arch Ophthalmol. 1988;106(7):898-900.

17. Susanna R Jr, Hatanaka M, Vessani RM, Pinheiro A, Morita C. Correlation of asymmetric glaucomatous visual field damage and water-drinking test response. Invest Ophthalmol Vis Sci. 2006; 47(2):641-4.

18. Lopes FS, Dorairaj S, Junqueira DL, Furlanetto RL, Biteli LG, Prata TS. Analysis of neuroretinal rim distribution and vascular pattern in eyes with presumed large physiological cupping: a comparative study. BMC Ophthalmol. 2014;14(1):72.

19. Prata TS, Dorairaj S, Trancoso L, Kanadani FN, Biteli LG, Furlanetto R, et al. Eyes with large disc cupping and normal intraocular pressure: using optical coherence tomography to discriminate those with and without glaucoma. Med Hypothesis Discov Innov Ophthalmol. 2014;3(3):91-8.

20. The Advanced Glaucoma Intervention Study (AGIS): 7. The relationship between control of intraocular pressure and visual field deterioration.The AGIS Investigators. Am J Ophthalmol. 2000; 130(4):429-40. Comment in: Am J Ophthalmol. 2000;130(4):490-1. 
21. Bengtsson B, Leske MC, Hyman L, Heijl A, Early Manifest Glaucoma Trial Group. Fluctuation of intraocular pressure and glaucoma progression in the early manifest glaucoma trial. Ophthalmology. 2007;114(2):205-9.

22. Kass MA, Heuer DK, Higginbotham EJ, Johnson CA, Keltner JL, Miller JP, et al. The Ocular Hypertension Treatment Study: a randomized trial determines that topical ocular hypotensive medication delays or prevents the onset of primary open-angle glaucoma. Arch Ophthalmol. 2002;120(6):701-13.

23. Medeiros FA, Weinreb RN, Zangwill LM, Alencar LM, Sample PA, Vasile C, et al. Long-term intraocular pressure fluctuations and risk of conversion from ocular hypertension to glaucoma. Ophthalmology. 2008;115(6):934-40.

24. Caprioli], Coleman AL. Intraocular pressure fluctuation a risk factor for visual field progression at low intraocular pressures in the advanced glaucoma intervention study. Ophthalmology. 2008;115(7):1123-9. Comment in: Ophthalmology. 2009;116(4):817.
25. Asrani S, Zeimer R, Wilensky J, Gieser D, Vitale S, Lindenmuth $\mathrm{K}$. Large diurnal fluctuations in intraocular pressure are an independent risk factor in patients with glaucoma. J Glaucoma. 2000; 9(2):134-42. Comment in: J Glaucoma. 2000;9(6):487-8.

26. Weinreb RN, Garway-Heath DF, Leung C, Medeiros FA, Liebmann J. World Glaucoma Association Consensus. Diagnosis of primary open angle glaucoma. Amsterdam: Kluger; 2016.

27. Nicolela MT, Drance SM, Rankin S), Buckley AR, Walman BE. Color Doppler imaging in patients with asymmetric glaucoma and unilateral visual field loss. Am J Ophthalmol. 1996;121(5):502-10.

28. Kuba GB, Austermann P, Kroll P. Ocular blood flow in patients with asymmetric glaucoma. Ophthalmologe. 2002;99(11):835-8.

29. Prata TS, De Moraes CG, Kanadani FN, Ritch R, Paranhos A Jr. Posture-induced intraocular pressure changes: considerations regarding body position in glaucoma patients. Surv Ophthalmol. 2010;55(5):445-53. 